\title{
Aging: Time, Timing, Genetics, and Environment
}

\author{
Diego Iacono ${ }^{1,2,3}$ \\ ${ }^{1}$ Biomedical Sciences, Biomedical Research Institute of New Jersey (BRInj), USA \\ ${ }^{2}$ Neuropahology Research, BRInj and Mid-Atlantic Neonatology Associate (MANA), USA \\ ${ }^{3}$ Atlantic Neuroscience Institute, Atlantic Health System (AHS), USA
}

*Correspondence to: Diego Iacono, Neuropathology research, Biomedical Research Institute of NJ, BRInj 140 E. Hanover Avenue, Cedar Knolls, NJ 07927; USA; Email: iacono@brinj.org

Received: September 18, 2017; Accepted: September 25, 2017; Published: September 25, 2017;

\section{Editorial}

Time and timing represent some of the most influential aspects of human and animal life. Defining time has historically been, and continues to be, one of the toughest challenges for the minds of philosophers, theologians, physicists, biologists, and lay people [1-3]. Although the definition of time is a "hard problem" in philosophy, and philosophy of science in particular, and an exhaustive description of it is far from being proposed, the experience of time and timing is a very common one. We need to be on time for an appointment, music is essentially timing, circadian rhythm is about different temporal phases of our day, seasons have timing, human history is a continuous series of relevant and less relevant timed events.

In a neurobiological perspective, timing is about spatio-temporal coordination of events beginning from the moment of conception until to the end of life. While the concept of timing in neuroembriology and brain development in general, seems to be easier to grasp, and in fact it finally started to be considered by researchers as an essential aspect to consider to better understand highly complex genetic and neuroanatomical events of the central nervous system (CNS) during its formation [4-6], an operational concept and definition of timing during aging has been instead, much less considered. Investigating specific genetic, neuroanatomical, neuroplasticity, and long-term environmental aspects that could model human brain function and neuroanatomical structures (?) during the last temporal phases of human life has received much less attention.

Importantly, focusing on the molecular mechanisms (and at a larger scale at clinical level as well) of timing aspects in an older brain imply also to take in account that the CNS is part of an organism with other apparatuses and systems that are integrated (with their own timings) to each other and that can have functional consequences on each other.

A series of fundamental questions still remain unanswered, for example: what is the timing of those molecular phenomena determined by gene activations and "residual?" neuroplasticity capacities in a centenarian brain? Are there "pathologic experiences" during inutero life that could be temporarily buffered (for example, thanks to neuroplasticity and adaptive/compensatory synaptic capacities of the human CNS - with possible additional positive effects from the interaction of the CNS with beneficial environmental stimulation such as education, physical and intellectual exercising, and other) and so determine a clinically normal brain functioning during infancy, youth and early adulthood, but that can later manifest (or re-manifest) at different levels of clinical severity (e.g. from isolated cognitive disorders such as mild cognitive impairment (MCI) to dementia - e.g. Alzheimer's disease or Parkinson's disease)? Which are the relative biological influence, or intrinsic biological power, of programmed (genetic) and non-programmed (environment, traumatic brain injury, unbalanced nutrition, etc.) factors? How can those factors be reliably quantified at clinical level?

Albert Einstein defined time as a quantity [7], but which are the effects of those temporal quantitative aspects on the human brain? Is aging a neurodevelopmental timing going backwards as to infancy? Which are the temporal (and neuroanatomical?) synchronized events in relationship to those genes determining those peculiar biological (neuronal) events characterizing the period of life that we conventionally termed aging? Is longevity a question of biological timing? If so, which are the internal "clocks" that establish that timing?

At the beginning of this new editorial adventure, we ought to receive investigations describing these fascinating aspects of human life: time, timing, genetics and environment as interplay of events across the lifespan, and especially across the brain lifespan.

Giving the opportunity to either senior and junior investigators in the field of aging to submit their scientific works to our new journal will potentially offer the tremendous opportunity to contribute to a more detailed understanding of human biology during aging [8-10], and especially the biology of the brain during human aging, and so shed light on the mysteries of this still so unknown and surprising organ.

\section{References}

1. St. Augustine, Confessions (2012) Simon \& Brown Publishers.

2. Martin Heidegger (1962) Being and Time. Translated by John Macquarrie \& Edward Robinson. London: SCM Press, United Kingdom.

3. Clarke EF (1999) Rhythm and Timing in Music, in: Diana Deutsch (ed.), Psychology of Music, $2^{\text {nd }}$ (edn) University of California, San Diego, USA: pp 473-500.

4. Sarnat HB, Philippart M, Flores-Sarnat L, Wei XC (2015). Timing in neural maturation: arrest, delay, precociousness, and temporal determination of malformations. Pediatr Neurol 52: 473-486. [crossref]

5. Acosta M, Gallo V, Batshaw ML (2002) Brain development and the ontogeny of developmental disabilities. Adv Pediatr 49: 1-57. [crossref] 
6. Hua JY, Smith SJ (2004) Neural activity and the dynamics of central nervous system development. Nat Neurosci 7: 327-332. [crossref]

7. Einstein A (1916) Relativity: The Special and General Theory (Translation 1920) New York: H. Holt and Company, USA.

8. Jin K (2010) Modern Biological Theories of Aging. Aging Dis 1: 72-74. [crossref]

9. Jones OR, Vaupel JW (2017) Senescence is not inevitable. Biogerontology Aug 28. [crossref]

10. Greenberg E, Vatolin S (2017) Symbiotic origin of aging. Rejuvenation Res. [crossref]

\section{Citation:}

Diego Iacono (2017) Aging: Time, Timing, Genetics, and Environment. Ageing Sci Ment Health Stud Volume 1(1): 1-2 